\title{
INTERNACIONALIZAÇÃO \\ DE EMPRESAS NO MUNDO \\ PERIFÉRICO: UM ESTUDO DE CASO \\ DA CONSTRUTORA NORBERTO ODEBRECHT
}

Firm internationalization in the peripheral world: a case study of

Construtora Norberto Odebrecht

Pedro Giovannetti Moura ${ }^{\mathrm{a}}$

(D) https://orcid.org/0000000301046417

E-mail: pedrogimoura@hotmail.com

a Universidade de São Paulo, Instituto de Estudos Brasileiros, São Paulo, SP, Brasil 


\title{
RESUMO
}

O presente artigo tem por objetivo colocar em debate possíveis paradigmas que joguem luz ao processo de internacionalização da Construtora Norberto Odebrecht (CNO). Argumentamos que o modelo, hoje, mais difundido pelos grandes meios de comunicação é ancorado no conceito de Capitalismo de laços, sintetizados em obra de Sérgio Lazzarini. Buscamos nos distanciar dessa chave analítica e propor uma outra que, com base em uma compreensão global da história e na primazia de condicionantes locais, situa a atuação internacional da construtora em dois momentos chave. Em um primeiro, nos anos 1980 e 1990, entendemos que a empreiteira opta pela região latino-americana devido a uma somatória de fatores como: (a) o aproveitamento dos gargalos de infraestrutura da região latino-americana condicionados aqui pelo próprio modelo de desenvolvimento periférico da região; (b) os benefícios de atuar sobre uma região que é órbita de influência geopolítica brasileira; e (c) sua proximidade geográfica. Já a partir dos anos 2000 , defendemos que essa prática de internacionalização passa por uma mudança. Consolidada enquanto empresa transnacional, a CNO passa a se valer da estratégia do governo brasileiro de conformação de grupos 'campeãs nacionais' como forma de ampliar sua inserção no mercado internacional. Para embasar essa linha argumentativa, nos valemos da combinação entre obras que tratam do desenvolvimento periférico junto à análise de fontes públicas e internas - como a Revista Odebrecht Informa -, disponibilizadas pela empresa. Dessa forma, pretendemos historicizar a internacionalização da empreiteira, construindo, para tanto, paradigmas interpretativos de análise desse processo que coloquem em relevo a relação entre condicionantes do subdesenvolvimento e a internacionalização de empresas.

\section{PALAVRAS-CHAVE}

História empresarial; História econômica; História contemporânea.

\begin{abstract}
This article aims to discuss paradigms that might shed some light on the process of internationalization of Construtora Norberto Odebrecht (CNO). We argue that this model — currently more widely disseminated on account of the great means of communication - is underpinned by the concept of "capitalismo de laços" [networked capitalism], which is outlined in the work of Sérgio Lazzarini. We aim to disengage from this analytical perspective and propose another one, based on a global understanding of history and on the primacy of local constraints. This new approach perceives CNO's international practice in two key moments. From 1980 to 1990, the construction company chooses the Latin-American region due to a series of factors, such as: (a) to benefit from the infrastructure of the Latin-American region - resulting from its specific peripheral-based model of development; (b) to work in a region greatly influenced by Brazilian geopolitics; (c) the geographical proximity. On the other hand, we believe that from 2000 onwards this internationalization practice changes. Consolidated as a transnational firm, CNO starts to draw on the Brazilian government's strategy of forming "national champions" as a means to enhance its presence in the international market. To support this argumentation, we draw on the combination of works that approach the peripheral development in addition to an analysis of public, internal sources - such as the Odebrecht Informa newsletter - made available by CNO. Thus, we intend to historicize the internationalization of this construction company, based on the elaboration of interpretive paradigms to analyze this process by emphasizing the relation between underdevelopment constraints and the internationalization of firms.
\end{abstract}

\section{KEYWORDS}

Business history; Economic history; Contemporary history. 
$\mathbf{A}$ simbiótica atuação entre a Operação Lava-Jato e os grandes meios de comunicação trouxe ao centro da arena pública a discussão sobre a atuação internacional da Construtora Norberto Odebrecht (CNO), e, sob um mais amplo diapasão, das empresas brasileiras e daquelas oriundas das periferias da economia mundial como um todo. A importância da CNO, especificamente, se explica por, na primeira década dos anos 2000, a empreiteira chegar ao posto de principal construtora de engenharia pesada brasileira e do continente americano (NORBERTO ODEBRECHT..., 20 jul. 2012), além de — no ano de 2008 - deter o segundo posto em ranking elaborado pela Fundação Dom Cabral acerca do índice de transnacionalidade das empresas nacionais (FUNDAÇÃO DOM CABRAL, 2008).

Essa ampla inserção internacional da empreiteira foi analisada, especialmente nos grandes meios de comunicação latino-americanos, como decorrente de um modus operandi calcado na construção de vínculos pessoais entre representantes da empresa e agentes dos Estados (GASPAR, 2020) do qual decorreria uma prática capitalista deturpada, corrompida e 'mafiosa' (GIUFFRA, 2015; ROLDÓS, 2017; ROSSI, 2017). Assim, um dos grandes motivos para o sucesso da empreiteira estaria na construção de relações $\square$ não republicanas $\square$, pautadas na pessoalidade entre empresas privadas e agentes públicos, que garantem condições privilegiadas à empresa, conformando aquilo que Sergio Lazzarini conceitua enquanto "capitalismo de laços". ${ }^{1}$

Os textos dos jornalistas, assim, não devem ser diminuídos enquanto ensaios de opinião pessoal, mas vistos como espécie de ponta de lança pública de um conceito criado num espaço acadêmico, que reforça uma construção argumentativa que ganha força no debate. Na visão de Lazzarini, esse Capitalismo de laços se trata de um modelo assentado no uso de relações particulares para explorar oportunidades de mercado ou para influenciar determinadas decisões de interesses. Conforma-se, assim, em um $\square$ emaranhado de contatos, alianças e estratégias de apoio gravitando em torno de interesses políticos e econômicos $\square$ (LAZZARINI, 2018, p. 4).

De forma que, corrupção, clientelismo, privilégios e favorecimentos, escassez de crédito e burocracia ineficiente, além de ingerência estatal nas transações próprias do mercado são, na visão do autor, pedras angulares do nosso "capitalismo de laços”, maculado e disfuncionado pela atuação estatal (GUIOT, 2012, p. 94). Essa amálgama entre esfera privada e pública, por sua vez, seria decorrente da ausência de "instituições que promovam e facilitem o funcionamento de seus mercados", instituições capazes de intermediar as relações entre vendedores e compradores, o que torna essa relação "menos transparente e mais dificultosa". É justamente a ausência desses intermediários que abriria caminho aos Institucional Voids, espécies de gaps que representam a singularidade primordial das economias emergentes nessa visão (KHANNA; PALEPU, 2010, p. 19). ${ }^{2}$

\footnotetext{
${ }^{1}$ A formulação de Lazzarini não deve ser vista como um raio em céu azul. Há uma vasta tradição intelectual brasileira, e mesmo estrangeira, que, historicamente, acaba por conformar uma espécie de corrente de pensamento que interpreta que o Estado abriga uma "elite corrupta que vampirizaria a nação", segundo a crítica empregada por Jessé Souza. (SOUZA, 2017, p. 12). André Guiot, em resenha do livro de Lazzarini, aponta como o autor e os teóricos tributários do patrimonialismo como ferramenta de articulação da dinâmica Estado e Sociedade, acabam por converter o Estado como um sujeito de si mesmo, entidade quase a parte da atuação das classes sociais (GUIOT, 2012, p. 95).

${ }^{2}$ Aqui, novamente, os postulados dos autores dialogam com uma cristalizada matriz teórica. Alexandre Barbosa argumenta haver uma tradição recente de pensamento "mainstream" ocidental que articula
} 
Não corroboramos, no entanto, com essa chave de analítica. Primeiro, porque não interpretamos o "capitalismo original" como um "capitalismo sem laços", enquanto uma espécie de 'sistema etéreo', livre da ação e atuação de agentes sociais particulares historicamente constituídos. Julgamos mais interessante, aqui, nos valer da visão de Braudel, para quem o elemento definidor do capitalismo encontra-se na camada do 'contramercado', que representa, em realidade, a manipulação da própria economia de mercado, ao ser capaz de alterar rotas, especular, estocar e sabotar o "ordenamento natural do mercado" (BRAUDEL, 1987, p. 38-46) e se converter, assim, no "reino da esperteza e no direito do mais forte" (BRAUDEL, 2009, p. 197). ${ }^{3}$

Assim, mais do que lócus capacitador de instituições que garantiriam a imparcialidade estatal para o bom funcionamento da "mão invisível" do mercado, livre de interferências externas, pretendemos argumentar em favor da compreensão desse espaço de interconexões entre grandes empresas e Estado enquanto uma visible hand, nos valendo aqui dos termos de Chandler (1999). Logo, nos parece inerente à economia capitalista a articulação entre agentes das grandes empresas multinacionais e aparatos do Estado.

Em segundo lugar, não nos valemos, nesse artigo, dos postulados sintetizados pelo conceito do "Capitalismo de laços", pois a análise histórica da internacionalização da CNO nos aponta para outros fatores enquanto eixos estruturantes desse processo. Resumidamente, enxergamos na internacionalização da CNO um movimento de atuação exitoso - do ponto de vista empresarial - que se estrutura em dois momentos cruciais.

Projetamos demonstrar como o primeiro deles foi o preenchimento, por parte da empreiteira - a partir dos anos 1980 - de um gargalo de obras infra estruturais e integrativas na região latino-americana. A partir de alguns postulados cepalinos, enxergamos, na região, um quadro de: (a) limitação do progresso técnico; (b) baixa produtividade; e (c) deficiência de obras de infraestrutura (FURTADO, 1969; PREBISCH, 2011; RODRÍGUEZ, 2009). Assim, junto às facilidades logísticas propiciadas pela proximidade geográfica e o suporte dado pelo Estado brasileiro, a construtora se vale desse hiato local para espraiar sua atuação pela região.que lócus capacitador

Já como segundo momento desse processo de internacionalização da empreiteira, aponta-se como - a partir dos anos 2000, durante os governos Lula — é empregada pelo governo brasileiro uma política de grupos "campeões nacionais", projetando empresas com atuação internacional já consolidada a ampliar sua inserção mundial. ${ }^{4}$ Já consolidada em fins dos anos 1990 enquanto uma empresa transnacional, - além de obras em diversos países latino-americanos, nesse momento a CNO já

determinados tipos de desenvolvimentos à adoção (ou não) de determinadas instituições organizativas. Como exemplos aponta as obras de Douglas North e sua crítica às instituições ineficientes, e na diferenciação conceituada por Daron Acemoglu entre Espanha e Inglaterra no contexto da Revolução Industrial (BARBOSA, 2020).

3 Essa relação umbilical entre grandes empresas capitalistas - que atuariam na camada do 'contramercado', valendo-se dos termos braudelianos - e Estado foi tema de vasta literatura que, em comum, explicita como os grandes conglomerados não decorrem unicamente de um êxito empresarial particular, mas, pelo contrário, se associam em diferentes níveis com instâncias estatais que lhes garantes acesso a contatos, ativos e condições privilegiadas não acessadas pelos ocupantes dos demais "andares". Ver, por exemplo: Schumpeter (2010, p. 143), Galbraith (1982, p. 59), Dicken (1998, p. 223) e Mazzucato (2019, p. 29).

${ }^{4}$ Sobre o tema dos grupos campeões nacionais, ver: Aghion (2011), Amsden (2009) e Coutinho (2002). 
estava presente em países de outros continentes, como Angola, Portugal, Estados Unidos - , a empresa vê seu grau de inserção mudar de patamar devido ao acesso a maiores fontes de financiamento e novos clientes.

Em suma, pretendemos explicitar como, mais do que a constituição de uma rede de vínculos pessoais 'não republicanos' com agentes estatais, o êxito da internacionalização da construtora reside em práticas "eminentemente capitalistas": uma correta adequação de táticas empresariais a partir de condicionantes particulares de sua principal base de atuação - a América Latina. Ora se valendo dos gargalos, ora aproveitando-se de uma readequação da postura do Brasil frente ao processo integrativo regional, a CNO é capaz de ampliar sua atuação e se postar enquanto importante player regional.

Portanto, partimos de uma visão segundo a qual nossa lente opera entre o total e o local a todo instante, reforçando interconexões entre aspectos empresariais, de política nacional e condicionantes do subdesenvolvimento regional. Projetamos, assim, realizar uma história de caráter global que compreenda o aspecto desigual assumido pelo desenvolvimento em diferentes espaços (AMIN, 2010, p. 2) e que, por extensão, nos relembre que as conexões - no caso entre agentes capitalistas e Estados - são precedidas por condicionantes e que, sem o entendimento dessas, se torna impossível a compreensão daquelas (CONRAD, 2016, p. 69-70). Ao não hierarquizar espaços segundo instituições fracas ou insuficientes, mas sim enquadrálos enquanto áreas com complementariedade, interdependência e desiguais atividades econômicas (RIOJAS; RINKE, 2016, p. 11) que logramos construir paradigmas capazes de melhor auxiliar no objetivo de esmiuçar a internacionalização de empresas em países subdesenvolvidos.

Tendo em vista esse objetivo, nas páginas subsequentes nos debruçamos sobre a análise desses dois grandes momentos da internacionalização da CNO. A partir do cruzamento e balanço entre bibliografia sobre a CNO, fontes públicas e fontes internas disponibilizadas pela empresa, se projeta uma breve historicização da internacionalização da construtora. Na primeira parte analisamos os anos 1980-1990, com as lentes voltadas para a atuação da empreiteira na América Latina, base de sua atuação internacional; já na segunda parte, tratamos dos anos 2000 e o cenário de ampliação de escopo geográfico e escala de atuação da construtora a partir da política de grupos líderes nacionais dos governos Lula.

\title{
CHARCANI, COLBÚN-MACHICURA E SANTA ELENA: 0 PRIMEIRO MOMENTO
}

\begin{abstract}
Quem viaja para a América do Sul ou viaja muito pelo Brasil, normalmente, encontra a mão da Odebrecht em alguma coisa. Eu penso que não são muitos os quilômetros de estradas brasileiras que a gente pode percorrer sem passar por um quilômetro de asfalto feito pela Odebrecht. [...] Eu acho, Emílio, que a Odebrecht é motivo de orgulho para qualquer brasileiro que viaje o mundo. Acho que a Odebrecht, em competência, não deve à país nenhum do mundo, a escola de engenharia nenhuma do mundo [...] (Discurso do Presidente Lula apud GASPAR, jan. 2020, p. 25).
\end{abstract}


Excetuando os adjetivos da declaração do ex-Presidente Lula, os quais estão à cargo de juízo de valor particular, seu discurso no aniversário de sessenta anos da Holding Odebrecht traz consigo dois aspectos importantes. Iniciamos pelo fim: a Construtora Norberto Odebrecht, parte integrante e mais antiga da Holding Odebrecht, é uma empresa do ramo da engenharia pesada ${ }^{5}$ que, historicamente, promoveu obras no Brasil, América Latina e em países centrais.

Embora oriunda de um país no qual não são desenvolvidas, primordialmente, atividades que controlam uma grande parte do excedente total produzido dentro da cadeia de mercadorias - isto é, de uma área central —, podemos situar o Brasil em uma posição intermediária dentro da economia mundial. Consideramos, aqui, o Estado brasileiro enquanto integrante daquilo que Arrighi conceituou como região semiperiférica, isto é, uma região caracterizada pela convivência entre atividades típicas do núcleo central e periférico em seu interior. Ou: "Estados [que] têm o poder de resistir a periferização, embora não [tenham] poder suficiente para superá-la completamente e passar a fazer parte do núcleo orgânico" (ARRIGHI, 1997, p. 140).

Porém, essa condicionante não justifica, sozinha, o fortalecimento da indústria da construção pesada no país. À parte características particulares da história do país - como os projetos de desenvolvimento capitaneados por Getúlio Vargas e Juscelino Kubitschek, que ampliam a demanda por empresas desse porte (DRAIBE, 1985, p. 13 e 84-88) - Ferraz Filho salienta a existência de "especificidades" do ramo industrial da engenharia pesada. Ao nosso ver, esses particularismos desse ramo industrial são determinantes para justificar seu desenvolvimento em países não dotados de grande desenvolvimento técnico-científico.

Tal singularidade pode ser explicada por três pontos. Em primeiro lugar, na construção pesada, há a possibilidade de se fragmentar obras ou contratar outras empresas para serviços específicos que não exigem da construtora uma grande mobilização de capital. Em segundo lugar, a própria garantia de um contrato pode significar os meios de conseguir recursos para a aquisição de alguns equipamentos. Por fim e, talvez mais significativamente, Ferraz considera que a questão tecnológica não representa uma barreira à entrada do capital privado no ramo:

além de a tecnologia vir embutida no próprio equipamento, é possível absorver técnicas de construção no próprio ato de construir. No caso da necessidade em adquirir conhecimentos mais avançados, é sempre possível a contratação de uma consultora ou firmar alianças com firmas estrangeiras (FERRAZ FILHO, 1981, p. 86-87).

Em suma: para o ramo da construção pesada, mais importante que a atividade tecnológica em si, está a capacidade da companhia se relacionar com os diferentes agentes estatais, logrando um espaço de atuação privilegiado. Em outros termos, por ser a construção pesada uma área de atuação que não carrega em si grande

\footnotetext{
${ }^{5}$ Compreendemos a indústria da construção pesada (também chamada de empreiteiras) como o setor econômico que abrange as empresas dedicadas às obras de infraestrutura. Tais empresas são responsáveis por empreendimentos contratados comumente pelo Estado, sendo responsáveis por obras de transporte, energia, saneamento, urbanização, obras industriais, dutos, além de portos e aeroportos (CAMPOS, 2014, p. 2).
} 
complexidade tecnológica (FERRAZ FILHO, 1981, p. 94), é historicamente possível e observável a ocupação desse ramo industrial por empresas oriundas de zonas semiperiféricas. Assim sendo, sublinhar a competitividade da CNO junto à demais empresas estrangeiras da área no discurso supracitado não nos parece um equívoco.

Em segundo lugar, nos detemos ao início da afirmação do ex-Presidente: quem viaja para o Brasil ou América Latina, principalmente, encontra a "mão da Odebrecht em alguma coisa". Voltemo-nos agora, então, à compreensão dos fatores que balizam essa larga presença da empresa na região.

Com início de sua trajetória em 1945, na Bahia, a CNO operava enquanto uma empresa de engenharia pesada de alcance regional até finais dos anos 1950. Essa situação começa a se alterar quando, em 1954, a empresa se torna cliente da Petrobras com a obra do oleoduto Catu-Candeias. Sequencialmente, a empresa volta a realizar obras de construção de instalações de apoio, estações de tratamento de água, plataformas marítimas, pontes, canais, barragens, armazéns, casas de força, dragagens, laboratórios, residências, clubes, oficinas e rodovias (NOVONOR, c2020). ${ }^{6}$

A despeito de algumas inovações que garantiram seu crescimento, como, por exemplo, a realização simultânea de todas as etapas de suas construções substituindo a então consagrada técnica de levantamento de estrutura primeiro, paredes e rebocos depois - responsável por maior agilidade na entrega das obras (DANTAS, 2007, p. 77), é notório que os vínculos políticos estabelecidos com os órgãos de governos estatais ${ }^{7}$ foram condição imperiosa para a ascensão da Construtora. No início dos anos 1970, a então 19ª maior construtora brasileira (atrás, entre outras, da também nordestina Queiroz Galvão) muda de patamar, deixando de ser uma construtora com respaldo regional para se "nacionalizar" (CAMPOS, 2015, p. 100).

As vitórias em licitações no Rio de Janeiro para a construção do campus da Universidade do Estado do Rio de Janeiro (UERJ), do edifício-sede da Petrobras (aproveitando-se de ligação estabelecida com Geisel, ex-comandante da Petrobras e então Presidente do Brasil), do Aeroporto Internacional do Galeão e da Usina Termonuclear Angra, entre 1970 e 1976, alçam a CNO a um novo status (NOVONOR, c2020).

Embora nacionalmente consolidada e vivendo um ciclo de grandes obras no país - como o Complexo Hidrelétrico Pedra do Cavalo, em Cachoeira, na Bahia, o Sistema de Abastecimento de Água Riachão Potengi, no Ceará, e o Complexo siderúrgico da Açominas, em Ouro Branco, Minas Gerais -, o Grupo Odebrecht se encontrava ante um cenário de dificuldades com a retração do mercado da construção pesada no país. O montante de obras encurtara pela metade entre 1975 e 1976, passando de cerca de U\$14 bilhões para U\$7 bilhões (ODEBRECHT INFORMA, 1988a, p. 19).

Conforme refletia retrospectivamente o então Presidente do grupo, Emílio Odebrecht (2008, p. 8), a organização se encontrava ante um impasse: seguir a opção por diversificar os negócios, fortalecer a posição de engenharia no país mediante aquisições ou ir para o exterior. A opção foi pelos três: entre 1979 e 1985, a então

\footnotetext{
${ }^{6}$ Com a mudança recente de nome da Holding Odebrecht para Novonor, os materiais de seu antigo site migraram para um novo domínio.

${ }^{7}$ Malu Gaspar aponta como Norberto Odebrecht, então presidente da CNO, e o General Geisel, homem forte da Petrobras e futuro presidente da estatal entre 1969 e 1973, passam a deter um canal aberto de diálogo após as primeiras obras realizadas pela construtora para a estatal (GASPAR, 2020, p. 48-50).
} 
construtora adentra no negócio da petroquímica, convertendo-se, assim, em uma Holding; adquire construtoras concorrentes, como a Tenenge e a CBPO; e, por fim, assinava seu primeiro contrato internacional (ODEBRECHT INFORMA, 2004b).

Definida a internacionalização enquanto estratégia empresarial, nos atemos, agora aos porquês da escolha da região sul-americana como ponto de partida e principal base de atuação da construtora. Renato Martins, então responsável pelo Desenvolvimento de Negócios na Holding Odebrecht, afirma que:

Vários fatores determinaram nossa caminhada rumo a outros países a partir da América do Sul: proximidade geográfica, melhor possibilidade de coordenação e apoio, maior suporte do Governo brasileiro naquela época e proximidade de idioma e cultura. Identificamos países que desejavam receber uma colaboração, efetivada por meio de nosso trabalho e da aplicação de nossa tecnologia [...] (ODEBRECHT INFORMA, 1995, p. 4).

Segundo o executivo, assim, três são os principais fatores pela escolha da região: (a) proximidade cultural; (b) proximidade geográfica; (c) maior suporte do governo. Quanto ao primeiro, uma análise de outras publicações da organização denota como, na prática, foi necessário a conformação de equipes compostas majoritariamente de trabalhadores locais para contribuir com essa "aclimatação cultural", de forma que a citada proximidade cultural não nos parece um fator tão definidor como os demais (ODEBRECHT INFORMA, 1981; 1987; 1988a).

Nos debrucemos agora sobre o segundo fator. Proximidade geográfica não deve ser restrita à distância das viagens a serem realizadas pelos engenheiros, mas, principalmente, reforça-se seu impacto na agilidade de transporte de equipamentos e redução de custos operacionais envolvidos. Nesse sentido, uma análise sobre o tamanho e a importância assumidas pelas bases de apoio internacionais da empresa reforçam esse entendimento.

O volume 112 da Revista Odebrecht Informa traz um especial sobre a Base de Apoio Internacional (BAI) da Holding, localizada na zona norte do Rio de Janeiro.

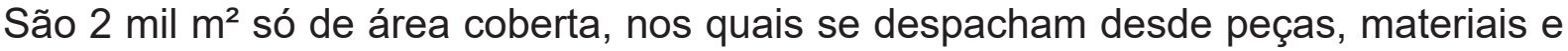
equipamentos destinados à execução de obras, tais como tratores ou vigas, até objetos de uso particular, como frutas ou objetos de higiene pessoal (ODEBRECHT INFORMA, 2004a, p. 30). Dessa forma, o estabelecimento de contratos em localidades próximas constitui enorme facilitador à logística do transporte dessa vasta gama de materiais necessários e à continuidade das atividades da empresa em solo estrangeiro.

Por fim, analisemos o último fator apontado por Martins, de ordem mais geopolítica: o estímulo e o suporte oferecidos pelo governo brasileiro para o crescimento interno e externo da Construtora, seja através do fornecimento de recursos mediante o convênio de crédito recíproco, seja mediante o estabelecimento de contatos privilegiados junto à governos locais.

Luiz Almeida, responsável por Desenvolvimento de Negócios e integrante do Conselho de Administração da Odebrecht S.A. também reforça esse elo entre empresa e governo brasileiro: "A atuação se baseava na visão estratégica de que deveríamos buscar boas oportunidades e, especialmente, onde houvesse interesse do governo brasileiro em estreitar relações com o país cliente" (ODEBRECHT INFORMA, 1994, p. 19). 
A respeito dessa vinculação entre empresa e governo brasileiro, não é acaso que a assinatura do primeiro contrato internacional da CNO - a construção da Hidrelétrica de Charcani, na região de Arequipa, no Peru - seja parte integrante da declaração conjunta entre os presidentes João Figueiredo (1979-1985) e Morales Bermúdez (1975-1980), do Peru, durante visita deste ao Brasil. Objetivando reafirmar a importância de se manter a integração dos países latino-americanos, o contrato assinado entre a Electroperu e a CNO, em consórcio com a Harrison Overseas Construction (Canadá) - que detinha $10 \%$ da obra - estipula um crédito entre 0 Banco do Brasil e o Governo do Peru, no valor de US\$ 89 milhões (ODEBRECHT INFORMA, 1980, p. 11).

Situada $35 \mathrm{~km}$ a nordeste de Arequipa, segunda cidade mais importante do Peru, a Usina Charcani V, com capacidade geradora de $135 \mathrm{Mw}$, rapidamente tornase a principal Usina do Rio Chili, importante veio local. A demanda pela obra, por parte do governo peruano, é explicada pela incapacidade das cinco outras Usinas da região (Charcani I, II, III, IV e VI) de abastecer Arequipa e as indústrias de mineração locais, já que totalizam um potencial de $35 \mathrm{Mw}$, insuficiente para uma demanda local ao redor de $60 \mathrm{Mw}$. A obra foi considerada de grande dificuldade técnica: $95 \%$ das atividades realizadas seriam subterrâneas, em uma região da Cordilheira dos Andes constantemente sujeita a abalos sísmicos (ODEBRECHT INFORMA, 1980, p. 12).

Asegunda obra internacional da CNO se dá no Chile, em 1981, com a realização do desvio do Rio Maule, na região de Maule, zona central do país andino, para a construção da Hidrelétrica de Colbún-Machicura. Esta abastecia a região central do Chile, entre Santiago e Concepción, e era responsável por um terço da demanda energética do país. A "conquista" da obra se deu através de um consórcio no qual, junto à Odebrecht, participou a brasileira Engesa e que teve a coordenação de Otávio Medeiros - chefe do Serviço Nacional de Informações no governo Figueiredo. (GASPAR, 2020, p. 69).

A obra inicia-se com a construção de dois túneis paralelos, revestidos de concreto, com seção livre de $220 \mathrm{~m}^{2}$, e culmina na construção final de duas Hidrelétricas, com capacidade geradora final de $890 \mathrm{Mw}$. Como resultado da obra, há um substancial aumento do potencial energético regional, que possibilita irrigar uma vasta região agrícola (ODEBRECHT INFORMA, 1981, p. 14). Marc Altit — líder da negociação para assinatura de contrato no Peru —, afirma que "Charcani e Colbún-Machicura foram nosso jardim de infância” (ODEBRECHT INFORMA, 1994, p. 18).

Por fim, seguindo a ordem cronológica dos países nos quais a CNO passa a atuar e, reforçando a proximidade junto ao governo brasileiro como eixo de importância para explicar essa internacionalização da Construtora, analisemos o caso equatoriano. Em um país definido por pensadores cepalinos como uma espécie de "economia de enclave" (FAJNZYLBER, 1983, p. 157), com um modelo econômico baseado na exportação de matérias-primas, o Equador era então um país cuja área propícia para agricultura era de apenas $6 \%$ - com culturas como banana, cacau, café, mandioca e batata. Esse setor representava $12 \%$ do PIB local e era responsável por absorver metade da população economicamente ativa do país (ODEBRECHT INFORMA, 1988a, p. 15).

É tendo em mente esse contexto que o governo local adota um amplo programa de irrigação para o país, com destaque especial para a península de Santa Elena, na costa equatoriana, área considerada de importância estratégica para o país. Com 45 mil hectares, a região enfrenta fortes problemas climáticos, já que $90 \%$ de suas 
chuvas se dão entre os meses de janeiro e abril. Aproveitando as águas do Rio Daule, o projeto buscou o alargamento das fronteiras agropecuárias do país, atendendo à crescente demanda interna de alimentos (ODEBRECHT INFORMA, 1988a, p. 17).

Aobra da península de Santa Elena não só marca a entrada da CNO em mais um país latino-americano, como consolida uma forma de atuação característica, pautada pelo envolvimento direto de órgãos do Estado brasileiro como facilitadores dessa empreitada. Orçada, à época, em US\$ 200 milhões, a obra conta com financiamento do Banco do Brasil, através da Carteira de Comércio Exterior do Banco do Brasil (CACEX). Como contrapartida, além da projeção de uma empresa nacional no exterior e o posterior pagamento do financiamento, ela gera exportações brasileiras de bens de capital de aproximadamente US\$48mi, e de bens intermediários e de consumo durável de quase US\$33mi. (ODEBRECHT INFORMA, 1988b, p. 9). Mas não só: o apoio dado pelo Estado brasileiro não se restringe apenas ao aporte financeiro, como assinalado por Roberto Abdenur, então embaixador brasileiro em Quito. A exportação de serviços manufaturados, assim, transforma o Brasil em um dos quatro principais parceiros comerciais do Equador.

A diplomacia brasileira, logo, mantém atuação direta no apoio aos exportadores de produtos e serviços. A própria obra de Santa Elena é detectada e comunicada pela embaixada brasileira em Quito às empresas nacionais de construção pesada. Ademais, completa o embaixador, a embaixada é responsável direta pela criação de redes de contato entre o empresariado nacional e o governo equatoriano, ao promover missões comerciais e eventos como feiras de catálogos, bem como, principalmente, por importante lobby junto ao governo brasileiro, o que facilita a importação de produtos equatorianos (evitando uma possível retaliação comercial por parte dos andinos). Isso culmina em um acordo em que a Petrobras se responsabiliza pela compra de dez mil barris/dia de petróleo provenientes daquela nacionalidade (ODEBRECHT INFORMA, 1988b, p. 11).

Consequentemente, em fins dos anos 1980, mais de 1/3 de todo conjunto de obras da CNO se encontrava em mercados internacionais (NOVONOR, c2020).

É a partir desses três países que a presença da CNO se irradia para o continente, entre os anos 1980 e 1990: Argentina, com a construção da Hidrelétrica de Pichi Picún Leufú, em 1987; México, Venezuela e Colômbia, com as obras da barragem de Los Huítes, o Centro Comercial de El Lago e a ferrovia La Loma — Santa Marta, respectivamente, em 1992, além de novas obras no Peru, como os canais de Chavimochic, em 1995. Mas não só: esse período assiste à chegada da construtora em mercados de países centrais, como Portugal e Estados Unidos. (ODEBRECHT INFORMA, 1987, p. 22).

Ao longo de 30 anos, assim, a CNO passará a atuar em boa parte do continente americano, conforme podemos observar pelo mapa abaixo (Figura 1), que identifica países e período de início da atuação da construtora no local. 
Figura 1 - Países americanos com obras da CNO cronologicamente. 1980-2010

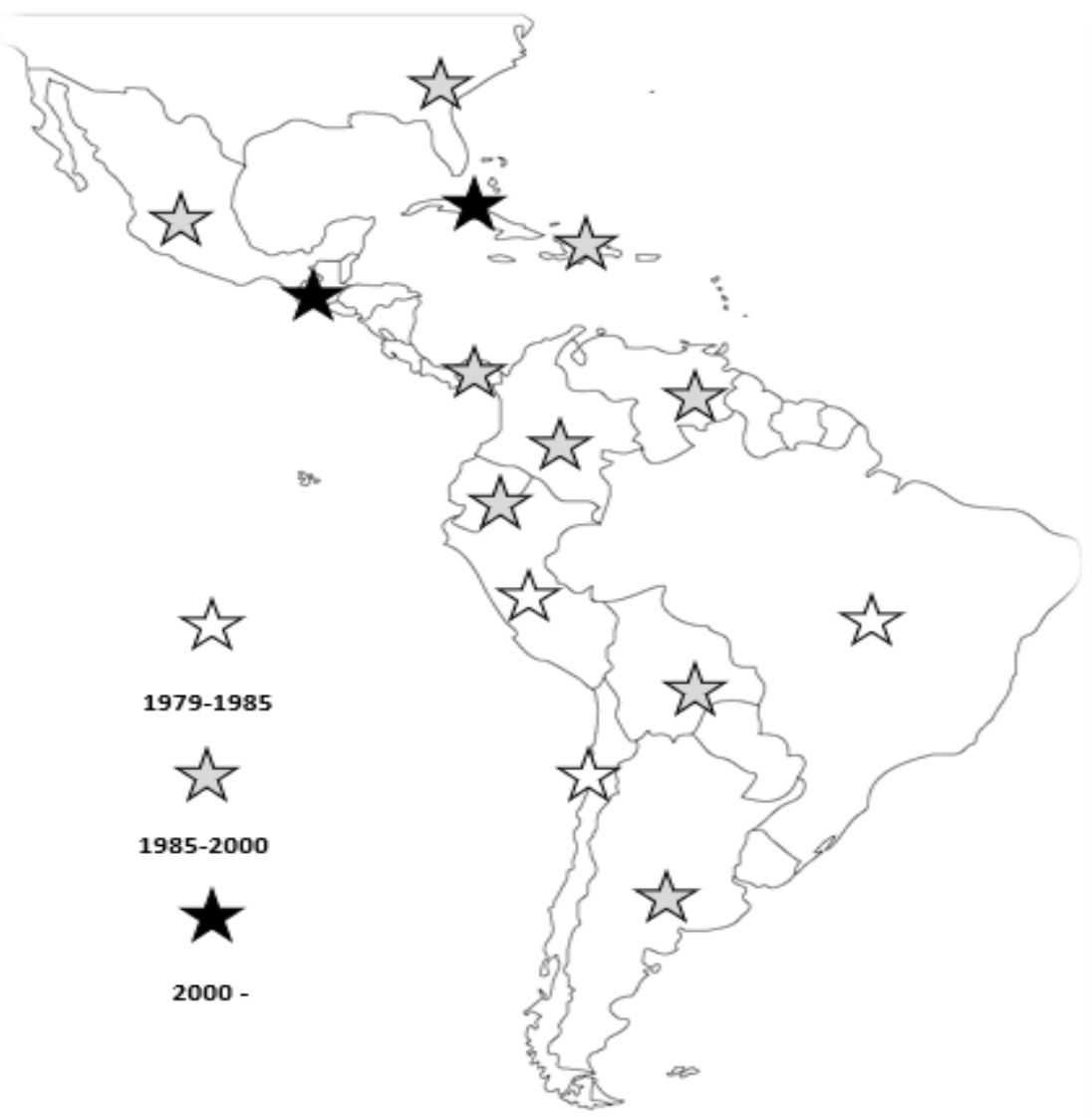

Fonte: Elaboração do autor (ODEBRECHT INFORMA, 1980, 1981, 1987, 1988a, 1994, 2004b; NOVONOR, c2020).

Por fim, cabe aqui apontarmos um último e preponderante fator que explica essa priorização à região latino-americana: sua demanda por obras de infraestrutura. Com um processo histórico que conformou países não dotados de sequer uma integração nacional, a América Latina era um grande celeiro de obras. Para se ter uma ideia: a primeira obra peruana, por exemplo, projetava solucionar o déficit energético da segunda maior cidade do país; Colbún-Machicura, no Chile, tratava-se de 1/3 da energia elétrica de Santiago, capital nacional; e Santa Elena, no Equador, almejava contribuir para as colheitas de uma área estratégica em um país que $12 \%$ de seu PIB decorre da agricultura. Assim sendo, as obras não representam pequenos detalhes, mas sim eixos centrais para a conformação de uma infraestrutura regional.

Para se ter ideia desse "déficit de infraestrutura", a primeira obra de ligação energética na América do Sul foi um gasoduto ligando Argentina e Bolívia somente em 1988. E, até os anos 2000, não havia nenhum oleoduto interligando dois países na região (NARCISO; SENNES, 2009). Assim, é justamente sobre esse contexto de vazios de projetos robustos que as empresas da engenharia pesada e, especialmente a $\mathrm{CNO}$, se valem para atuar regionalmente.

Dessa forma, podemos assumir, inicialmente, que a internacionalização da CNO decorre de uma estratégia traçada pela construtora com o objetivo de ampliar e diversificar seus ativos em um cenário de retração do mercado de obras nacional. A escolha de sua principal "base" internacional recai, entre os anos 1980 e 1990, sobre a região latino-americana. $E$ isso se explica por, simultaneamente, a região apresentar 
facilidades logísticas decorrentes de uma proximidade geográfica; se configurar enquanto órbita de influência da geopolítica brasileira, facilitando a construção de uma rede de contatos e financiamentos; e, primordialmente, por ser uma região com um grande gargalo de obras de infraestrutura, sobre o qual a empresa se vale nesses anos para consolidar sua atuação regional.

\section{ANOS 2000: DA CONSOLIDAÇÃO INTERNACIONAL À "CAMPEÃ NACIONAL"}

A partir de fins dos anos 1990 passamos a considerar a CNO enquanto uma empresa transnacional. As definições sobre os conceitos de internacionalização e transnacionalização variam de forma recorrente entre os mais diversos autores. Alguns, como Dalla Costa (2011, p. 10), optam pela simplificação ao enquadrá-las sob um mesmo espectro. Já outros optam por uma hierarquização em diferentes estágios, a depender do grau de inserção internacional da empresa.

Em um primeiro momento teríamos a estruturação da empresa enquanto grande empresa nacional, em um processo de concentração de capital. Em um segundo a diversificação - assumindo-se como Holding e atuando em distintos negócios - e o início da atividade internacional — ancorada na contribuição de seu Estado nacional. ${ }^{8}$ Por fim, teríamos a empresa transnacional, atuando em escala mundial, com: (a) coordenação e controle de vários estágios de cadeias produtivas em diferentes países; (b) habilidade de tomar vantagens geográficas e políticas estatais para ampliar sua capacidade produtiva; (c) flexibilidade geográfica para mudar suas fontes de operações entre diferentes localizações geográficas (CHESNAIS, 1996, p. 73-74; DICKEN, 1998, p. 177; DOELINGER; CAVALCANTI, 1979, p. 9).

Ora, o processo abordado ao longo do artigo dialoga de forma direta com a processualidade apontada pelos autores: (i) o fortalecimento nacional da $\mathrm{CNO}$, garantido pelo estabelecimento de redes de contatos privilegiados junto ao aparelho estatal durante o período da Ditadura Militar no Brasil; (ii) sua diversificação nos anos 1970, ampliando sua gama de atuação — primeiro, a partir da entrada no ramo da Petroquímica, convertendo-se, assim, em uma Holding -, concomitantemente a processos de aquisição de outras grandes empresas - das quais se destacam a CBPO e a Tenenge; (iii) a contribuição do Estado brasileiro para sua internacionalização, sendo peça-chave no primeiro contrato firmado com o governo de outro país - o Peru - e atuando enquanto ponte com o Estado equatoriano, nos anos 1980; (iv) por fim, sua organização em escala mundial, expressa por sua presença em quatro continentes já nos anos 1990 com coordenação de vários estágios de cadeias produtivas em diferentes países, capacidade de tomar vantagens geográficas e de políticas, e flexibilidade geográfica.

É nesse cenário, já enquadrada enquanto empresa transnacional,que analisamos as modificações dos anos 2000. Primeiramente, em 1999, é lançada a Iniciativa para a Integração da Infraestrutura Regional Sul-Americana (IIRSA), um

\footnotetext{
${ }^{8} \mathrm{~A}$ importância dessa base nacional é também salientada por Peter Dicken. O autor argumenta de forma contrária à tese de que a transnacionalização de empresas representa uma desnacionalização destas, ao apontar o quão, mesmo após consolidada sua atuação internacional, as empresas se mantêm fortemente afetadas pelas especificidades de seu país base (DICKEN, 1998, p. 193).
} 
programa conjunto dos governos dos 12 países da América do Sul. Buscava-se, com o programa, mediante a conformação de uma infraestrutura física desses países (modernização dos transportes, energia, telecomunicações), ampliar seu grau de integração mundial. (MARIANO, 2014, p. 247).

A adoção de um programa com dinheiro do BID, CAF, FONPLATA e, principalmente, do Banco Nacional de Desenvolvimento (BNDES), resultando na realização de obras essenciais para as economias, é de grande importância para a região. Afinal, ampliam-se obras nacionais de infraestrutura que são pré-requisitos para promover uma integração capaz de sair da abstração teórica a nível continental. Evidentemente, nesse cenário, a $\mathrm{CNO}$, então construtora brasileira com maior presença e adensamento nas economias locais devido ao seu número de obras na região e à sua presença nas sociedades nacionais, vale-se da IIRSA para ampliar seu repertório de obras.

Para ilustrar: apenas no Peru, nos anos 2000, a Holding passa a atuar com quatro concessionárias: a IIRSA Norte, IIRSA Sur, Ruta del Sol e Rutas del Lima. ${ }^{9}$ Essas sucursais foram responsáveis, a título de exemplo, pela pavimentação dos trechos Iñapari-Puerto Maldonado-Inambari; Inambari-Juliaca; Inambari-Cusco, partes integrantes da construção do Corredor Viário Interoceânico Sul. Além dessas obras, podemos apontar, no país andino, a ampliação da capacidade das rodovias Tarapoto-Yurimaguas e Paita-Tarapoto, concluídas em 2009 e 2011, respectivamente. Os dois projetos somam $1.041 \mathrm{~km}$ de rodovias e contam com 10 pontos de pedágio, conectando da Amazônia ao pacífico.

Concomitante a abertura desse amplo mercado de obras - sobre o qual a CNO se debruçará - destaca-se uma mudança na política industrial brasileira que pode ser vista enquanto uma tentativa de fortalecer alguns setores estratégicos nacionais. Inicialmente, podemos mensurar essa mudança pela criação de órgãos públicos de promoção do desenvolvimento industrial e, principalmente, na adoção de uma nova linha política adotada pelo BNDES.

Para Saulo de Almeida, medidas estabelecidas pelos governos Lula (20032010) - como, a título de exemplo, a reformulação da Agência Brasileira de Promoção de Exportações e Investimos (APEX); a instituição do Programa de Mobilização da Indústria Nacional de Petróleo e Gás Natural (PROMINP); a criação do Comitê de Financiamento e Garantia de Exportações (COFIG); o lançamento da Política Industrial, Tecnológica e de Comércio Exterior (PITCE); (ALMEIDA, 2012, p. 15-16) seriam indicativas da preocupação do Governo com a ampliação da capacidade e da competitividade de nossas indústrias. Aponta o autor que:

é possível observar que nos últimos anos nos aprofundamos um pouco sobre o simplório conceito de que uma política industrial é um conjunto de medidas estatais que afetam direta ou indiretamente o desempenho industrial através de efeitos sobre variáveis microeconômicas e iniciamos um novo movimento, em que o objetivo da nossa política industrial não parece mais querer apenas maximizar a renda real média das empresas, mas contornar os custos e as incertezas na geração de inovações

\footnotetext{
${ }^{9}$ Todas as informações referentes às obras dessas quatro concessionárias da CNO podem ser extraídas
} do site: http://www.odebrechtlatinvest.com/activos/iirsa-sur.html. Acesso em: 28 mar. 2020. 
tecnológicas, inserindo os nossos agentes como reais players do mercado global (ALMEIDA, 2012, p. 12, grifos do autor).

Assim, mais que fomentar a ampliação da atividade industrial nacional, as políticas dos governos Lula objetivavam, a partir do reconhecimento de quais setores detinham potencialidade para uma inserção externa, dotá-los de maior capacidade para consolidar e ampliar seu nível de atuação na arena externa — grupos "campeões nacionais". Essa intervenção estatal, mediante subsídios para indústrias nascentes ou proteção para indústrias maduras, pode ser justificada, segundo Philippe Aghion, como um meio de acelerar as externalidades da produção, ponto nodal para o desenvolvimento dessas indústrias, sobretudo para países que se encontram atrás da corrida tecnológica do mercado mundial — ou países subdesenvolvidos (AGHION, 2011, p. 25-26; AMSDEN, 2009). ${ }^{10}$

Em textos e apresentações promovidas por importantes economistas do BNDES - como Demian Fiocca e Luciano Coutinho, presidentes do Banco, entre 2006 e 2016 - percebe-se o desenho dessa nova política industrial. Para Demian Fiocca, em apresentação na Firjan, a adoção de medidas por parte do BNDES, que objetivassem o fortalecimento de empresas nacionais com grande potencial e a promoção de sua internacionalização, alçando-as ao posto de multinacionais, se explica por essas representarem mais de $75 \%$ do comércio mundial, além de serem principais fontes de financiamento privado à pesquisa e ao desenvolvimento (FIOCCA, 2006, p. 4). ${ }^{11}$ Dessa análise, resulta um salto de liberações do banco para empresas nacionais: de uma média anual de US\$100 milhões, no início dos anos 1990, para US\$ 4 bilhões no início deste século; em 2005, desembolsos de apoio ao comércio exterior totalizam US $\$ 5,86$ bilhões, com crescimento de $51,8 \%$ em relação a 2004 (FIOCCA, 2006, p. 18).

Em 2002, Luciano Coutinho também já desenhava essa mudança paradigmática do BNDES. Para o autor, cumprir com o objetivo de acelerar a obtenção de ganhos de competitividade às empresas brasileiras - o que contribuiria com o desempenho do saldo comercial ao longo dos próximos anos - tem, como pré-requisito, a implementação de uma política industrial mobilizadora e bem estruturada, voltada para o comércio exterior. Nas palavras do autor: "A política industrial deve dar suporte à capitalização e à internacionalização das empresas brasileiras, especialmente nos setores em que o investimento direto no exterior é indispensável à expansão das exportações" (COUTINHO, 2002, p. 10).

Naturalmente, esse suporte à capitalização e à internacionalização das empresas brasileiras não se faz sem contrapartidas exigidas pelo Banco, buscando a garantia do desenvolvimento "nacional". Fiocca, em sua apresentação, defende o emprego de dispositivos contratuais que protejam o investimento do BNDES e promovam a adoção de práticas adequadas de governança corporativa (FIOCCA, 2006, p. 17). Estudo da LCA Consultoria aponta como aportes governamentais diretos e indiretos (através de concessões, benefícios, empréstimos via BNDES, entre outros) levam

\footnotetext{
${ }^{10}$ Sobre a intervenção do Estado com o intuito de gerar grupos campeões nacionais, ver, para estudos de caso, Eaton (2013) e Sudekum (2010). Já para um balanço global dessas políticas, sua definição e impactos, ver Amsden (2009, p. 335-400).

${ }^{11}$ Por ser uma apresentação disponibilizada na internet, não temos maiores informações sobre o dia/ local da mesma, tampouco sobre o público ao qual foi destinada.
} 
a uma exportação dos serviços de engenharia para diversos países - merecendo destaque os países do Mercosul e os africanos (LCA CONSULTORIA, 2014).

Para melhor ilustrar: de 2007 a 2015, o apoio do BNDES a exportações do setor de construção gera encomendas para 4.044 diferentes fornecedores brasileiros de bens e serviços. Nesse mesmo período, o número de pessoas empregadas nessa cadeia quase dobra, passando de 402 mil para 788 mil. ${ }^{12}$

Esmiuçando o papel jogado pelo CNO, especificamente: o Relatório Anual de 2007 aponta que o crescimento da construtora possibilita a geração de 190 mil empregos diretos e indiretos; contribui para o crescimento de 2.300 empresas brasileiras, fornecedoras de bens e serviços para as obras da Odebrecht no exterior; e gera US\$ 817 milhões em divisas para o Brasil. Já o Relatório Anual de 2009 aponta para um total de 1.598 empresas fornecedoras de bens para obras realizadas no exterior, sendo que, destas, $40 \%$ são formadas por pequenas e médias empresas. Com relação à prestação de serviços em geral, as obras no exterior da CNO contam 1.219 empresas; 2.817 é o número de empresas que a internacionalização da CNO mobiliza diretamente (ODEBRECHT S.A., 2007, 2009).

Se, até então, os financiamentos eram realizados mediante operações de renda variáveis, constituindo-se, assim, em investimentos indiretos sem destinação específica, a partir de 2002, é realizada uma alteração estatutária no BNDES. Esta é responsável por criar uma linha capaz de estimular a inserção e o fortalecimento de empresas nacionais no mercado internacional, desde que estas resultassem em estímulo à exportação de produtos domésticos (ALEM; CAVALCANTI, 2005. p. 68).

Consequentemente, a CNO, enquanto uma das grandes brasileiras de engenharia, vive um aumento de seu backlog. Para exemplificar: na Venezuela, a construtora recebe financiamento para realizar obras no Metro de Caracas, na construção das linhas dois e cinco, bem como do trecho El Valle-La Rinconada. No Equador, o financiamento contribui para as obras de transposição dos Rios Chone e Portoviejo, aproveitamento hidroelétrico do Rio San Francisco, construção da Usina de Manduriacu, construção e pavimentação de rodovias, e para o projeto de irrigação Trasvase Daule Vinces, a fim de otimizar o aproveitamento dos recursos hídricos próximos ao Rio Daule. Já na Argentina, financia: a ampliação da capacidade de transporte do Gasoduto General San Martin e dos gasodutos operados pela distribuidora Cammesa, a construção da Planta de tratamento e do sistema de distribuição de água de Paraná de Las Palmas; entre diversos outros. ${ }^{13}$

No ano de 2007, seu Relatório Anual destaca que a construtora atua diretamente em 18 países de quatro continentes, em 16 estados do Brasil, tocando mais de 160 obras simultâneas. Esse poderio da construtora é importantíssimo por catapultar os ativos totais do Grupo para ordem dos $\mathrm{R} \$ 23.094$ milhões, com um lucro líquido anual de R\$ 127 milhões (ODEBRECHT S.A., 2007, p. 3, 2009, p. 2).

Assim, as obras arrematadas em consórcios relacionados à IIRSA junto à disponibilização de linhas de crédito pelo BNDES, somado a capacidade de atuação desenvolvida pela construtora desde os anos 1979, com obras na região, são responsáveis por dois efeitos. Em primeiro lugar, por um aumento no tamanho da construtora, ampliando exponencialmente seu patamar de atuação. Mas não

\footnotetext{
${ }^{12}$ Disponível em: bndes.gov.org. Acesso em: 5 maio 2020.

${ }^{13}$ Disponível em: bndes.gov.org. Acesso em: 8 maio 2020.
} 
só: em nível regional, a escala desse crescimento impacta o próprio "mercado das construtoras", alterando de forma substancial a composição da carteira de obras de infraestrutura a nível regional. O mapa abaixo (Figura 2) contrasta o mercado de obras regional latino-americano antes e depois desse contexto de mudanças nos anos 2000:

Figura 2 - Obras de engenharia pesada realizadas na América Latina por origem nacional das empresas. $2004 \times 2012$
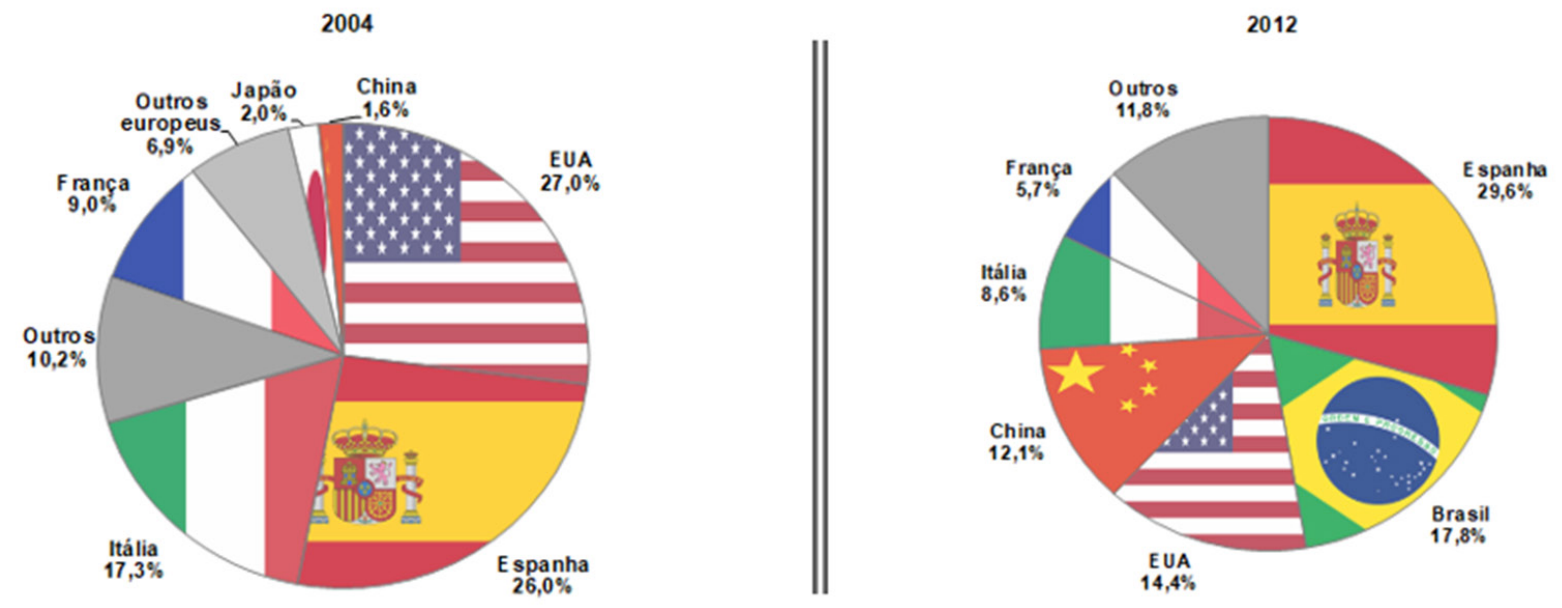

Fonte: Elaboração do autor (LCA Consultoria 2014, p. 31).

Assim que, embora a partir de fins dos anos 1990 já possamos caracterizar a CNO como uma empresa transnacional, os anos 2000 veem uma ampliação de alcance e escala significativa. Esses fatos podem ser expressos quando analisamos o número de países em que a construtora está presente (Figura 1), seu aumento de receitas e da indústria da construção pesada como um todo - e, ainda, quando analisamos a composição do mercado latino-americano de atividades para empreiteiras ao longo dos anos 2000.

Notamos, portanto, naquilo que consideramos um segundo momento de atuação da construtora, como determinadas políticas industriais instituídas tendo em vista maior projeção de empresas em um contexto de subdesenvolvimento lograram uma ampliação significativa das atividades da empreiteira. Projeta-se, assim, uma narrativa não linear da internacionalização da construtora, amparado por condicionantes e particularidades específicas de cada momento.

\section{CONSIDERAÇÕES FINAIS}

Tivemos por objetivo com esse artigo colocar em pauta a discussão sobre paradigmas sobre o processo de internacionalização da Construtora Norberto Odebrecht. Para tanto, buscamos, nas páginas acima, nos distanciar do modelo proposto por Lazzarini com seu conceito de Capitalismo de laços.

Aqui, cabe salientar que não negamos que muitos dos contratos firmados pela CNO prescindem do estabelecimento de relações ditas "não republicanas" envolvendo agentes de uma empresa transnacional e representantes dos órgãos de Estado. Pontuamos, por outro lado que, primeiramente, esse elemento sozinho não dá conta de explicar o processo de internacionalização da construtora e, em segundo lugar, 
que essas relações não se constituem enquanto singularidade do capitalismo latinoamericano, pautado por supostos "laços pessoais". Pelo contrário, vemos, nessas relações entre grandes empresas e Estado, "contrárias aos preceitos da imparcialidade do mercado", senão um aspecto constituinte do modelo capitalista como um todo, abarcando desde economias centrais a periféricas.

Assim, ao longo dessa página, nos propusemos, tendo em vista essa amálgama entre condicionantes regionais, atuação do Estado brasileiro e decisões empresariais, pontuar um outro modelo que levasse em conta a complexidade dessa atuação internacionalização a partir de uma chave de análise particular. Foi, assim, que construímos uma interpretação que balizou a internacionalização da CNO em dois momentos, marcados por condicionantes e especificidades históricas.

Sem a pretensão de esgotar o tema, esse artigo se propôs a contribuir com a história global contemporânea, reforçando o entendimento de que o estudo das empresas, de suas práticas de internacionalização e condicionantes particulares são fundamentais para o desenvolvimento de nossa disciplina nos tempos atuais.

\section{REFERÊNCIAS}

AGHION, Philippe. Some Thoughts on Industrial Policy and Growth. In: FALCK, Oliver; GOLLIER, Christian; WOESMANN, Ludger. Industrial policy for National Champions. Cambridge: The MIT Press, 2011. p. 13-31. (CESIFO Seminar Series).

ALEM, Ana Cláudia; CAVALCANTI, Carlos E. de Siqueira. O BNDES e o apoio à internacionalização das empresas brasileiras: algumas reflexões. Revista do BNDES, Rio de Janeiro, v. 12, n. 24, p. 43-77, 2005.

ALMEIDA, Saulo F. Caldeira. Campeões Nacionais: o papel do BNDES e a atuação do Sistema Brasileiro de Defesa da Concorrência. 2012. 85 f. Dissertação (Mestrado em Direito Político e Econômico) - Direito econômico, Universidade Presbiteriana Mackenzie, São Paulo, 2012.

AMIN, Samir. Global history: a view from the south. Oxford: Pambazuka Press, 2010.

AMSDEN, Alice H. A ascensão do "resto": os desafios ao ocidente de economias com industrialização tardia. São Paulo: Editora UNESP, 2009.

ARRIGHI, Giovanni. A ilusão do desenvolvimento. Rio de Janeiro: Editora Vozes, 1997.

BARBOSA, A. de Freitas. Ao invés de interpretá-lo, a esquerda edulcorou o capitalismo. Entrevista concedida ao Instituto Humanitas UNISINOS, São Leopoldo, 14 ago. 2020. Disponível em: http://www.ihu.unisinos.br/159-noticias/ entrevistas/601895-ao-inves-de-interpreta-lo-a-esquerda-edulcorou-o-capitalismobrasileiro-sem-perceber-suas-complexidades-entrevista-especial-com-alexandre-defreitas-barbosa. Acesso em: 20 out. 2020.

BRAUDEL, Fernand. A dinâmica do Capitalismo. Rio de Janeiro: Rocco, 1987. 
BRAUDEL, Fernand. Civilização material, economia e capitalismo: Séculos XV-XVIII, ss jogos das trocas. São Paulo: Martins Fontes, 2009.

CAMPOS, Pedro H. Pedreira. O processo de transnacionalização das empreiteiras brasileiras, 1969-2010: uma abordagem quantitativa. Tensões mundiais, Fortaleza, v. 10, n. 18/19, p. 103-123, 2014.

CAMPOS, Pedro H. Pedreira. Estranhas catedrais: As empreiteiras brasileiras e a ditadura civil-militar (1964-1988). Rio de Janeiro: EDUFF, 2015.

CHANDLER, Alfred D. The visible hand: the managerial revolution in American business. Cambridge: Harvard University Press, 1999.

CHESNAIS, François. A mundialização do capital. São Paulo: Xamã Editora, 1996.

CONRAD, Sebastian. What is global history? New Jersey, Princeton University Press, 2016.

DALLA COSTA, Armando J. Internacionalização de empresas brasileiras: Teorias e experiências. Curitiba: Juruá Editora, 2011.

COUTINHO, Luciano G. Marcos e desafios de uma política industrial contemporânea. In: CASTRO, Ana Célia (org.). Desenvolvimento em debate: painéis do desenvolvimento brasileiro I. Rio de Janeiro: Editora Mauad, 2002. v. 2, p. 191209.

DANTAS, Ricardo M. de Almeida Odebrecht: A caminho da longevidade saudável? 285 f. 2007 . Dissertação (Mestrado em Administração) - Instituto COPPEAD de Administração, Universidade Federal do Rio de Janeiro, Rio de Janeiro, 2007.

DICKEN, Peter. Global shift: transforming the world economy. New York: The Guilford Press, 1998.

DOELLINGER, Carlos von; CAVALCANTI, Leonardo C. Empresas multinacionais na Indústria Brasileira. Rio de Janeiro: IPEA, 1979.

DRAIBE, Sônia M. Rumos e metamorfoses: Estado e industrialização no Brasil, 1930-1960. Rio de Janeiro: Paz e Terra, 1985.

EATON, Sarah. Political Economy of the Advancing State: the case of China's airlines reform source. The China Journal, Chicago, n. 69, p. 64-86, jan. 2013.

FAJNZYLBER, Fernando. La industrialización trunca de América Latina. México, D.F.: Editorial Nueva Imagen, 1983.

FERRAZ FILHO, Galeno T. A transnacionalização da grande engenharia brasileira. 1981. 327 f. Dissertação (Mestrado em Economia) - Instituto de Filosofia e Ciências Humanas, Universidade Estadual de Campinas, Campinas, 1981. 
FIOCCA, Demian. O BNDES e a Internacionalização das Empresas Brasileiras. As novas multinacionais brasileiras, 2006, Rio de Janeiro. 29 maio 2006. 27 slides. Disponível em: https://web.bndes.gov.br/bib/jspui/handle/1408/6926. Acesso em: 19 set. 2020.

FUNDAÇÃO DOM CABRAL. Ranking FDC das multinacionais brasileiras. São Paulo: Fundação Dom Cabral, 2008.16f. Relatório de pesquisa FDC.

FURTADO, Celso. Desenvolvimento e subdesenvolvimento. Rio de Janeiro: Fundo da Cultura, 1969.

GALBRAITH, John K. O Novo Estado Industrial. São Paulo: Abril Cultural, 1982.

GASPAR, Malu. História de uma amizade. Revista Piauí, São Paulo, Edição 160, p. 16-26, jan. 2020. Disponível em: https://piaui.folha.uol.com.br/materia/historia-deuma-amizade. Acesso em: 28 mar. 2020.

GIUFFRA, Franco. Fala, Marcelo, por Franco Giuffra. El Comercio, Lima, 25 jun. 2015. Disponível em: https://elcomercio.pe/opinion/mirada-de-fondo/fala-marcelofranco-giuffra-166641-noticia/. Acesso em: 1 maio 2020.

GUIOT, André Pereira. Relações intercapitalistas e Estado no Brasil recente: novas pesquisas, antigos receituários. Revista História \& Luta de Classes, s.l. (online). n. 13, p. 94-96, 2012.

KHANNA, Tarun; PALEPU, Krishna G. Winning in the emerging markets: a road map for strategy and execution. Boston: Harvard Business Press, 2010.

LAZZARINI, Santiago G. Capitalismo de laços: os donos do Brasil e suas conexões. São Paulo: Bei Editora, 2018.

LCA CONSULTORIA. Exportação de Serviços de Engenharia no Brasil: benefícios para a economia brasileira e mecanismos de apoio. São Paulo, jan. 2014.

MARIANO, Marcelo Passini. O papel do Brasil na integração da infraestrutura da América do Sul: limites institucionais e possibilidades de mudança. In: DESIDERÁ NETO, Walter A. (org.). O Brasil e novas dimensões da integração regional. Rio de Janeiro: IPEA, 2014. p. 229-291.

MAZZUCATO, Mariana. O Estado empreendedor: Desmascarando o mito do setor público vs. setor privado. Tradução de Elvira Serapicos. São Paulo: Editora Schwarcz, 2019.

NOVOMOR. A Novonor. História. Salvador: Grupo Novonor, c2020 [online]. Disponível em: https://www.novonor.com.br/pt-br/a-novonor/historia. Acesso em: 5 out. 2021. 
ODEBRECHT S.A. Relatório Anual 2007/2008. [Salvador]: Odebrecht S.A., 2007. 52 p. Disponível em: https://www.novonor.com.br/sites/default/files/port_ra_ impressao_05_jun_2007.pdf. Acesso em: 4 out. 2021.

ODEBRECHT S.A. Relatório Anual 2008/2009. [Salvador]: Odebrecht S.A., 2009. 69 p. Disponível em: https://www.novonor.com.br/sites/default/files/relatorio_ anual_2009_portugues.pdf. Acesso em: 4 out. 2021.

NORBERTO ODEBRECHT é a maior empresa de engenharia e construção da América Latina, aponta ranking. Portal VGV, s.I. [online], 20 Jul. 2012. Disponível em: https://www.portalvgv.com.br/site/norberto-odebrecht-e-a-maior-empresa-deengenharia-e-construcao-da-america-latina-aponta-ranking . Acesso em: 8 maio 2020.

PREBISCH, Raúl. O desenvolvimento econômico da América Latina e alguns de seus principais problemas. In: GURRIERI, Adolfo (org.). O manifesto LatinoAmericano e outros ensaios. Rio de Janeiro: Contraponto, 2011a. p. 95-153.

ODEBRECHT INFORMA. n. 25, Salvador: Odebrecht S. A., 1980.

ODEBRECHT INFORMA. n. 27, Salvador: Odebrecht S. A, 1981.

ODEBRECHT INFORMA. n. 39, Salvador: Odebrecht S. A., 1987.

ODEBRECHT INFORMA. n. 40, Salvador: Odebrecht S. A., 1988a.

ODEBRECHT INFORMA. n. 41, Salvador: Odebrecht S. A., 1988b.

ODEBRECHT INFORMA. n. 61, Salvador: Odebrecht S. A, 1994.

ODEBRECHT INFORMA. n. 68, Salvador: Odebrecht S. A., 1995.

ODEBRECHT INFORMA. n. 112, Salvador: Odebrecht S. A., 2004a.

ODEBRECHT INFORMA. Edição Histórica 60 Anos. Salvador: Odebrecht S. A., 2004b.

RIOJAS, Carlos; RINKE, Stefan (org.). Historia global: perspectivas y tensiones. Guadalajara: Instituto de estudios latinoamericanos, 2016.

RODRÍGUEZ, Octavio. O estruturalismo latino-americano. Rio de Janeiro: Civilização Brasileira, 2009.

ROLDÓS, León. ¡A mí que me rebusquen! El Universo, Guayaquil, 18 set. 2017. Disponível em: https://www.eluniverso.com/opinion/2017/09/18/nota/6387238/mique-me-rebusquen/. Acesso em: 1 maio 2020. 
ROSSI, Clovis. Pactos de sangue mundo afora. Folha de São Paulo, São Paulo, 10 set. 2017. Disponível em: https://www1.folha.uol.com.br/colunas/ clovisrossi/2017/09/1917194-pactos-de-sangue-mundo-afora.shtml. Acesso em: 1 maio 2020.

SCHUMPETER, Joseph A. Capitalismo, socialismo e democracia. São Paulo: Editora UNESP, 2010.

SENNES, Ricardo U.; NARCISO, Thais. Brazil as an International energy player. In: BRAINARD, Lael; MARTINEZ-DIAZ, Leonardo (ed.). Brazil as an economic superpower? understanding Brazil's changing role in the global economy. Washington: The Brookings Institution, 2009. p. 17-55.

SOUZA, Jessé. A elite do atraso: da escravidão à Lava-Jato. Rio de Janeiro: Leya, 2017.

SÜDEKUM, Jens. National champions and globalization. The Canadian Journal of Economics/Revue canadienne d'Economique, Ottawa, v. 43, n. 1, p. 204-231, fev. 2010.

\title{
NOTAS DE AUTOR
}

\begin{abstract}
AUTORIA
Pedro Giovannetti Moura: Mestre. Universidade de São Paulo, Instituto de Estudos Brasileiros, São Paulo, SP, Brasil.
\end{abstract}

\section{ENDEREÇO PARA CORRESPONDÊNCIA}

Rua Diana, 231. Ap. 94, 05019-000, São Paulo, SP, Brasil.

\section{ORIGEM DO ARTIGO}

Extraído da dissertação de Mestrado "A internacionalização da Construtora Norberto Odebrecht: desenvolvimento e integração latino-americana", apresentada ao programa de Pós-Graduação em Cultura e Identidades Brasileiras, do Instituto de Estudos Brasileiros (IEB), da Universidade de São Paulo, em 2020.

\section{AGRADECIMENTOS}

Agradeço ao meu orientador Alexandre de Freitas Barbosa, além dos professores que participaram da banca de defesa - Professores Alvaro Comin, Pedro Henrique Campos e Tatiana Berringer.

\section{FINANCIAMENTO}

Não se aplica.

\section{APROVAÇÃO DE COMITÊ DE ÉTICA EM PESQUISA}

Não se aplica.

\section{CONFLITO DE INTERESSES}

Não houve conflito de interesses.

\section{LICENÇA DE USO}

(C) Pedro Giovannetti Moura. Este artigo está licenciado sob a Licença Creative Commons CC-BY. Com essa licença você pode compartilhar, adaptar e criar para qualquer fim, desde que atribua a autoria da obra. 


\section{PUBLISHER}

Universidade Federal de Santa Catarina. Programa de Pós-Graduação em História. Portal de Periódicos UFSC. As ideias expressadas neste artigo são de responsabilidade de seus autores, não representando, necessariamente, a opinião dos editores ou da universidade.

\section{EDITORES}

Flávia Florentino Varella (Editora-chefe)

Tiago Kramer de Oliveira

Waldomiro Lourenço da Silva Júnior

\section{HISTÓRICO}

Recebido em: 14 de março de 2021

Aprovado em: 28 de junho de 2021

Como citar: MOURA, Pedro Giovannetti. Internacionalização de empresas no mundo periférico: um estudo de caso da construtora Norberto Odebrecht. Esboços, Florianópolis, v. 28, n. 49, p. 854-875, set./dez. 2021 